\title{
Costoclavicular brachial plexus block reduces hemidiaphragmatic paralysis more than supraclavicular brachial plexus block: retrospective, propensity score matched cohort study
}

\author{
Chahyun $\mathrm{Oh}^{1, *}$, Chan Noh ${ }^{2, *}$, Hongsik Eom², Sangmin Lee ${ }^{2}$, Seyeon Park ${ }^{3}$, Sunyeul Lee ${ }^{1,2}$, Yong Sup Shin ${ }^{1,2}$, \\ Youngkwon $\mathrm{Ko}^{1,2}$, Woosuk Chung ${ }^{1,2}$, and Boohwi Hong ${ }^{1,2}$ \\ 'Department of Anesthesiology and Pain Medicine, College of Medicine, Chungnam National University, Daejeon, Korea \\ ${ }^{2}$ Department of Anesthesiology and Pain Medicine, Chungnam National University Hospital, Daejeon, Korea \\ ${ }^{3}$ College of Nursing, Chungnam National University, Daejeon, Korea
}

Received August 23, 2019

Revised December 6, 2019

Accepted January 20, 2020

\section{Correspondence}

Boohwi Hong

Department of Anesthesiology and Pain Medicine, Chungnam National University Hospital, College of Medicine, Chungnam National University, 282 Munhwa-ro,

Jung-gu, Daejeon 35015, Korea

Tel: +82-42-280-7840

Fax: $+82-42-280-7968$

E-mail: koho0127@gmail.com

*These authors contributed equally to this work.

\begin{abstract}
Background: Hemidiaphragmatic paralysis, a frequent complication of the brachial plexus block performed above the clavicle, is rarely associated with an infraclavicular approach. The costoclavicular brachial plexus block is emerging as a promising infraclavicular approach. However, it may increase the risk of hemidiaphragmatic paralysis because the proximity to the phrenic nerve is greater than in the classical infraclavicular approach.

Methods: This retrospective analysis compared the incidence of hemidiaphragmatic paralysis in patients undergoing costoclavicular and supraclavicular brachial plexus blocks. Of 315 patients who underwent brachial plexus block performed by a single anesthesiologist, 118 underwent costoclavicular, and 197 underwent supraclavicular brachial plexus block. Propensity score matching selected 118 pairs of patients. The primary outcome was the incidence of hemidiaphragmatic paralysis, defined as a postoperative elevation of the hemidiaphragm $>20 \mathrm{~mm}$. Factors affecting the incidence of hemidiaphragmatic paralysis were also evaluated.

Results: Hemidiaphragmatic paralysis was observed in three patients $(2.5 \%)$ who underwent costoclavicular and 47 (39.8\%) who underwent supraclavicular brachial plexus blocks $(P<0.001$; odds ratio, 0.04; 95\% confidence interval, 0.01-0.13). Both the brachial plexus block approach and the injected volume of local anesthetic were significantly associated with hemidiaphragmatic paralysis.

Conclusions: The incidence of hemidiaphragmatic paralysis is significantly lower with costoclavicular than with supraclavicular brachial plexus block.
\end{abstract}

Key Words: Anesthesia; Brachial Plexus Block; Diaphragm; Incidence; Nerve Block; Paralysis; Phrenic Nerve; Propensity Score; Retrospective Studies; Ultrasonography.

\section{INTRODUCTION}

Hemidiaphragmatic paralysis (HDP) is a frequent complication of the brachial plexus block, caused by uninten- tional blockade of the phrenic nerve, especially when the block is performed above the clavicle [1-7]. Although HDP can reduce forced vital capacity and forced expiratory volume at 1 second by $20 \%-30 \%$ [8-10], these reductions are (c) This is an open-access article distributed under the terms of the Creative Commons Attribution Non-Commercial License (http://creativecommons.org/licenses/by-nc/4.0/), which permits unrestricted non-commercial use, distribution, and reproduction in any medium, provided the original work is properly cited.

(c) The Korean Pain Society, 2020
Author contributions: Chahyun Oh: Writing/manuscript preparation; Chan Noh: Writing/manuscript preparation; Hongsik Eom: Investigation; Sangmin Lee: Investigation; Seyeon Park: Data curation; Sunyeul Lee: Writing/manuscript preparation; Yong Sup Shin: Supervision; Youngkwon Ko: Writing/manuscript preparation; Woosuk Chung: Methodology; Boohwi Hong: Study conception. 
generally well tolerated by most patients. HDP, however, can be a serious problem in some patients, including those with underlying lung disease or marginal pulmonary function [11-13].

Despite the incidence of HDP being lower after the supraclavicular brachial plexus block (SCB) than after the interscalene brachial plexus block, the incidence of HDP after the SCB has been reported to range from $30 \%$ $60 \%[1,2]$. The incidence of HDP after infraclavicular brachial plexus block is even lower [14,15], likely due to the relatively long distance between the phrenic nerve and the block site $[16,17]$. However, the infraclavicular brachial plexus block alone has limited utility in patients undergoing shoulder surgery because of the poor coverage of the proximal branch, such as the suprascapular nerve.

The costoclavicular brachial plexus block (CCB) is a recently introduced infraclavicular approach that targets three cords located lateral to the axillary artery in the costoclavicular space [18-21]. Cords in this space are located more superficially than with the classical approach at the lateral infraclavicular fossa and are clustered, while maintaining a consistent anatomical relationship with each other $[20,21]$. In addition, the costoclavicular space is considered a retrograde channel to the supraclavicular area, enabling reliable anesthesia, including anesthesia to the suprascapular nerve during shoulder surgery [22], and providing additional stability in catheter placement for a continuous brachial plexus block [23]. Because of these anatomical advantages, the CCB is emerging as a promising infraclavicular approach, with several studies showing that the CCB can provide a successful and rapid onset of the blockade with a single injection of a relatively small volume of local anesthetic [18-20].

The costoclavicular space is located proximal to the lateral infraclavicular fossa, providing greater proximity to the phrenic nerve. The CCB may therefore increase the risk of HDP, with one study showing that local anesthetic injected into the costoclavicular space reached the interscalene region, at the level of the primary trunk [24]. To date, however, no study has primarily assessed the incidence of HDP following the CCB. This retrospective propensity score matched cohort study therefore compared the incidence of HDP after the CCB with its incidence after the SCB.

\section{MATERIALS AND METHODS}

This retrospective observational study was approved by the Institutional Review Board of the Chungnam National University Hospital (IRB CNUH 2019-03-019) on March 28, 2019, and the trial was registered at the Clinical Research
Information Service, a clinical trial registry in South Korea (KCT0003764) on April 12, 2019. Informed consent was waived, due to the retrospective design of the study using medical records. This article adheres to the applicable STROBE (strengthening the reporting of observational studies in epidemiology) guidelines.

\section{Data collection}

The electronic medical records, as well as the picture archiving and communication system of all patients who underwent brachial plexus blocks, performed by a single anesthesiologist, in the Chungnam National University Hospital from January 2018 to December 2018 were reviewed retrospectively.

Patients were excluded if the brachial plexus block was performed using an interscalene or axillary approach, if their medical records were incomplete, or if the margins of the hemidiaphragm could not be distinguished on chest radiographs due to underlying lung pathology or poor image quality. Data collected from medical records included age, sex, height, weight, type of brachial plexus block, chest radiograph findings, postoperative $\mathrm{SpO}_{2}$ in room air, and injected volume of local anesthetic.

\section{Brachial plexus block}

All brachial plexus blocks were performed under ultrasound guidance by a single experienced anesthesiologist using an in-plane technique with Mylab ${ }^{\mathrm{TM}} 25$ Gold (Esaote, Genova, Italy) and a linear probe (LA435, 6-18 MHz; Esaote). Each patient was administered $20-30 \mathrm{~mL}$ of local anesthetic, consisting of a 1:1 mixture of $1 \%$ lidocaine and $0.75 \%$ ropivacaine.

In the CCB, patients were placed in a supine position with the surgical limb abducted 90 degrees. A transverse scan was performed immediately below the midpoint of the clavicle and over the medial infraclavicular fossa. Maintaining the same position, the transducer was gently tilted cephalad to direct the ultrasound beam toward the costoclavicular space, defined as the space between the posterior surface of the clavicle and the second rib. The ultrasound image was optimized until all three cords of the brachial plexus were visualized lateral to the axillary artery. Using an in-plane technique and a lateral-to-medial direction, the block needle was advanced until its tip was located in the middle of the three cords. Initially, $15-20 \mathrm{~mL}$ of local anesthetic was injected between the medial and posterior cord. The needle was then slightly withdrawn and its tip relocated to be adjacent to the lateral cord, and an additional 5-10 mL of anesthetic was injected (Fig. 1A, B) $[21]$. 

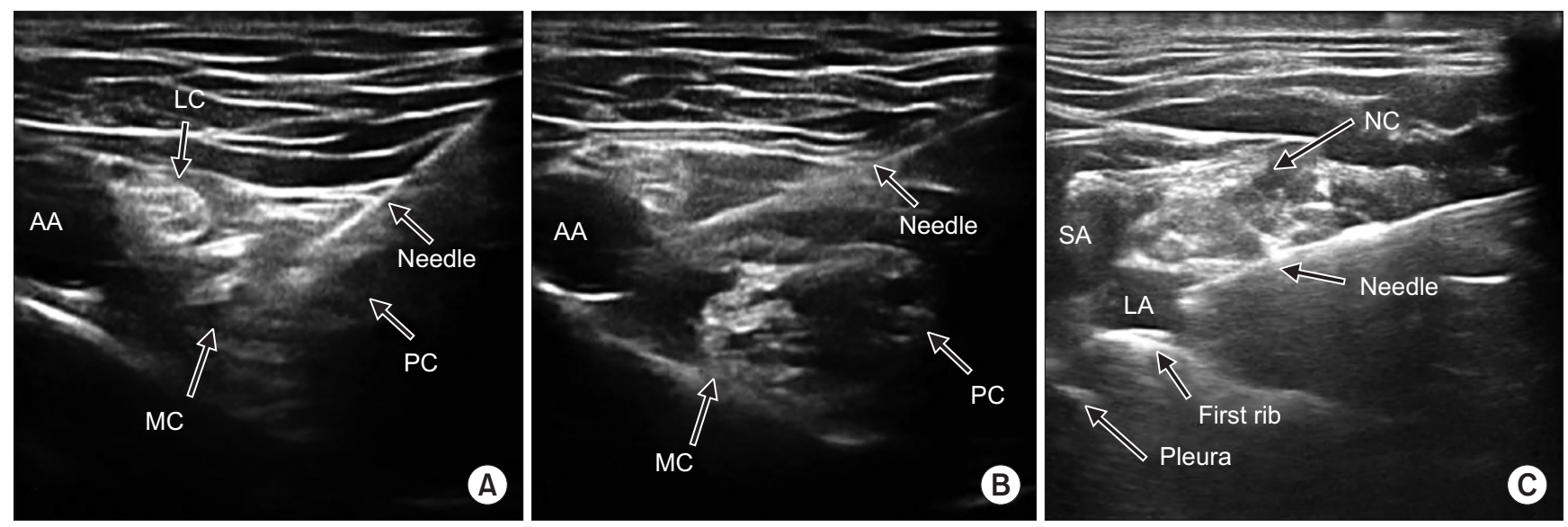

Fig. 1. Sonographic view of a brachial plexus in the costoclavicular space (A, B) and the supraclavicular region (C). (A) A block needle was inserted inplane in a lateral to medial direction, followed by initial injection of local anesthetic between the medial and posterior cords. (B) The needle was relocated adjacent to the lateral cord, followed by injection of additional anesthetic. (C) Initial injection of local anesthetic into the corner pocket, defined as the intersection between the first rib and the subclavian artery. Subsequent injection after relocation of the needle toward the neural cluster is not shown. AA: axillary artery, LC: lateral cord, MC: medial cord, PC: posterior cord, SA: subclavian artery, LA: local anesthetic, NC: neural cluster.
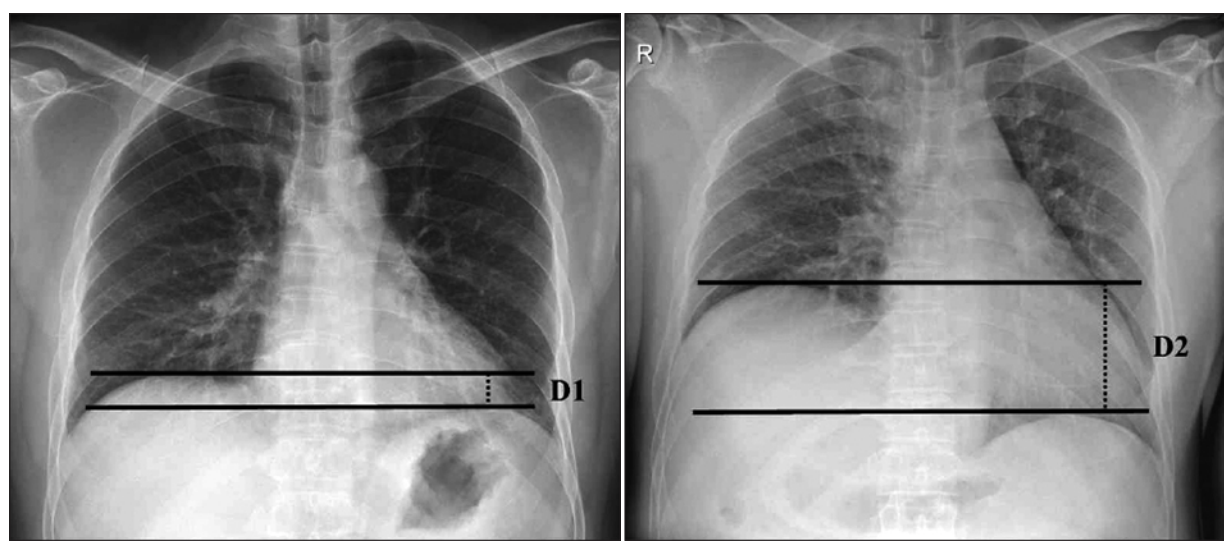

Fig. 2. Height measurement in a patient with right-sided hemidiaphragmatic paralysis on pre-operative (left) and postoperative (right) images. The vertical distance between the two lines (parallel to the vertebral body and passing through the highest points of each hemidiaphragm) was measured. The height of the right hemidiaphragm was determined relative to the height of the left hemidiaphragm, set at $0 \mathrm{~mm}$. The difference between preand post-operative heights was calculated as postoperative height (D2) - preoperative height (D1).
In the SCB, patients were placed in a supine position, with a soft (jelly) pad placed behind the back, and the head turned slightly to the contralateral side. A transverse scan was performed immediately above the clavicle. The transducer was gently tilted caudally to direct the ultrasound beam toward the first rib. The first target was the corner pocket (i.e., the intersection between the first rib and the subclavian artery) [25]. Subsequently, the needle was repositioned under direct vision, and directed toward the neural cluster formed by the trunks and divisions of the brachial plexus. Five to $10 \mathrm{~mL}$ of local anesthetic was injected into the corner pocket, followed by the injection of 15-20 mL between each trunk or division (Fig. 1C).

\section{Outcome measures}

The primary outcome was the incidence of HDP, defined as a $>20 \mathrm{~mm}$ elevation of the hemidiaphragm on chest radiographs. Elevation of the hemidiaphragm was deter- mined by comparing its relative position to that on the contralateral side on pre- and post-operative chest radiographs. The level of the hemidiaphragm was measured by drawing two lines parallel to the vertebral body that passed the highest points of each hemidiaphragm. The height of the hemidiaphragm was determined by adding or subtracting the vertical distance between these two lines on the contralateral hemidiaphragm (Fig. 2). The change of height was calculated by subtracting the preoperative height from the postoperative evaluation. For example, if the preoperative height of the hemidiaphragm on the surgical side was $-10 \mathrm{~mm}$ (i.e., $10 \mathrm{~mm}$ lower than on the non-surgical side) and the postoperative height was 20 $\mathrm{mm}$ (i.e., $20 \mathrm{~mm}$ higher than on the non-surgical side), the change of height would be $30 \mathrm{~mm}$, an amount diagnosed as HDP.

Preoperative chest radiographs were defined as those taken at the last clinic visit or one day before surgery. Postoperative chest radiographs were defined as those taken 
immediately after discharge from the postanesthesia care unit, as part of routine practice in our institution. Posteroanterior images were primarily assessed, with anteroposterior images assessed when posteroanterior images were not available. The usual clinical practice in our institution is to take posteroanterior images, but depending on the patient's condition, anteroposterior images may be taken instead.

Secondary outcomes were the occurrence of any respiratory symptoms after the brachial plexus block, such as dyspnea or chest discomfort, and room air $\mathrm{SpO}_{2}$, measured during the stay in the postanesthesia care unit. An exploratory analysis investigated factors associated with the occurrence of HDP.

\section{Statistical analysis}

All statistical analyses were performed using R software ver. 3.5.3 (R Project for Statistical Computing, Vienna, Austria). To account for possible selection bias and confounding factors [26], 1:1 propensity score matching was performed using the MatchIt package in R software [27]. The dependent variable was set as a binary response, with the CCB scored as 1 and the SCB as 0 . Nearest neighbor matching with a logistic regression-based propensity score was performed by designating the volume of local anesthetic, the preoperative height of the hemidiaphragm, the side of the operation, age, height, weight, and sex as covariates to be corrected. The absolute standardized difference was calculated to validate the matching of the two groups, with a difference $<0.1$ indicating that the two groups were sufficiently balanced.

After validating the balance of the matched data, the normality of continuous data was assessed using the Shapiro-Wilk test. If normality was satisfied, comparisons between groups were determined by independent $t$-tests, with the results expressed as mean \pm standard deviation. If normality was not satisfied, groups were compared using the Mann-Whitney $U$-test, with the results expressed as median (interquartile range). Categorical data were compared using the $\chi^{2}$-squared test or Fisher's exact test, as appropriate, with the results expressed as a number (\%). The primary outcome, the incidence of HDP, was compared by calculating odd ratio (OR) and $95 \%$ confidence interval (CI). For all calculations, a two-tailed $P$ value $<0.05$ was considered statistically significant.

To determine the factors affecting the occurrence of HDP, logistic regression analysis was performed using age, height, weight, sex, group, and volume of local anesthetic as explanatory variables. The volume of local anesthetic was calculated by subtracting the minimum volume used in this study $(15 \mathrm{~mL})$ from the original volume. Following univariate analysis, variables with $P$ values $<0.2$ were selected for multivariate backward stepwise regression. Akaike's information criterion was considered for final model selection. The Hosmer-Lemeshow test was performed to evaluate the goodness of fit of the model.

The results of the logistic regression analysis were considered as exploratory because this analysis was not predetermined.

\section{RESULTS}

During the study period, 426 patients underwent brachial plexus blocks; of these, 111 were excluded, including five with undistinguishable hemidiaphragm margins on chest radiographs, nine who underwent brachial plexus blocks on both sides, and 97 who underwent other types of brachial plexus blocks. Of the 315 remaining patients,

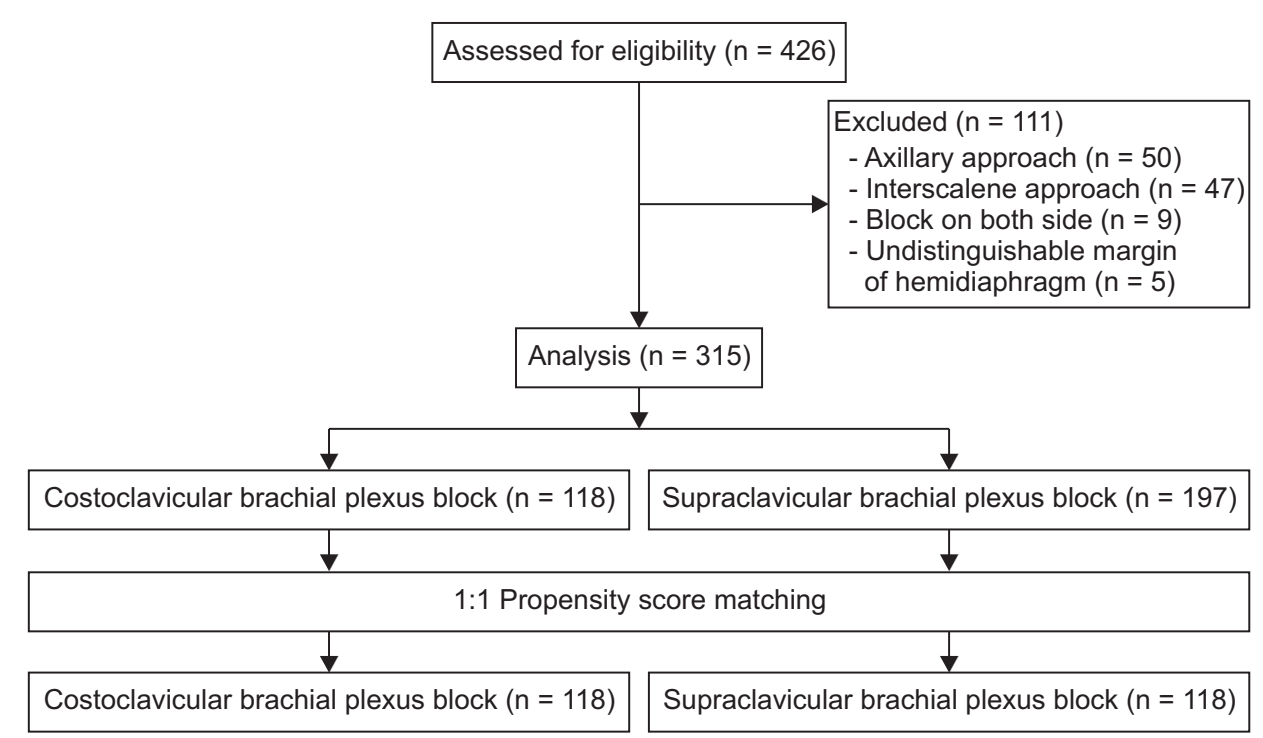

www.epain.org
Fig. 3. Flow diagram of patient selection and propensity score matching. 
118 underwent CCBs, and 197 underwent SCBs. Propensity score matching selected 118 pairs of patients (Fig. 3). The demographic and clinical characteristics of the two groups before and after matching are shown in Table $\mathbf{1 .}$ Before matching, the absolute standardized difference for weight was over 0.3 , indicating that weight affected the decision regarding which block to perform, with the ССВ preferentially performed in lighter patients. After matching, six covariates had acceptable absolute standardized differences of $<0.1$, whereas age did not. Although the absolute standardized difference of age did not meet the defined standard, the actual difference in age between the two groups was not statistically significant after matching $(P=0.267)$.

The incidence of HDP was $2.5 \%(\mathrm{n}=3)$ in patients who underwent CCBs and $39.8 \%(\mathrm{n}=47)$ in patients who underwent SCBs ( $P<0.001$; OR, 0.04; 95\% CI, 0.01-0.13). The three patients in the CCB group who experienced HDP received $25 \mathrm{~mL}$ of local anesthetic. The change in diaphragm height differed significantly in the CCB and SCB groups $(P<0.001$; Table 2). A histogram showing the changes in height of the hemidiaphragm is shown in Fig. 4. Postoperative room air $\mathrm{SpO}_{2}$ in the CCB and SCB groups differed significantly (98.0\% [97.0\%-98.0\%] vs. 97.0\% [96.0\%-98.0\%], $P=0.035$ ), but this difference was not significant clinically. Four pa- tients in the SCB group (3.4\%) reported chest discomfort.

Multivariate logistic regression analysis showed that the approach to the brachial plexus block and the volume of local anesthetic were significantly associated with the occurrence of HDP (Table 3). The final model could be expressed as follows ( $p$ indicates probability of HDP; sex: 1 for male; block approach: 1 for the CCB):

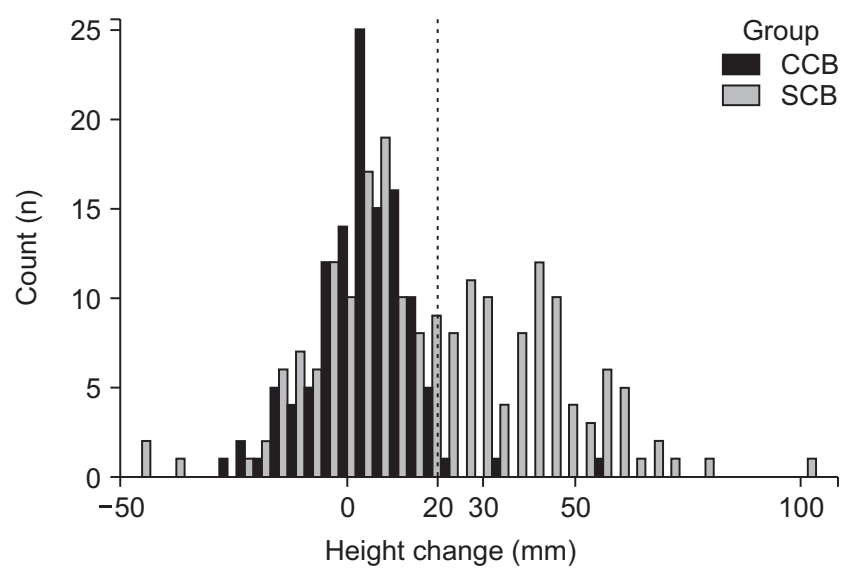

Fig. 4. Histogram showing changes in height of the hemidiaphragm. The dashed line indicates the cut off value for hemidiaphragmatic paralysis. CCB: costoclavicular brachial plexus block, SCB: supraclavicular brachial plexus block.

Table 1. Demographic and Clinical Characteristics of the CCB and SCB Groups Before and After Propensity Score Matching

\begin{tabular}{|c|c|c|c|c|c|c|}
\hline \multirow[b]{2}{*}{ Characteristic } & \multicolumn{3}{|c|}{ Unmatched data } & \multicolumn{3}{|c|}{ Matched data } \\
\hline & $\begin{array}{l}\text { CCB group } \\
(n=118)\end{array}$ & $\begin{array}{l}\text { SCB group } \\
(\mathrm{n}=197)\end{array}$ & ASD & $\begin{array}{l}\text { CCB group } \\
(n=118)\end{array}$ & $\begin{array}{l}\text { SCB group } \\
(n=118)\end{array}$ & ASD \\
\hline $\operatorname{Sex}(M / F)$ & $61 / 57$ & 90/107 & 0.12 & $61 / 57$ & $61 / 57$ & $<0.01$ \\
\hline Age (yr) & $53.5(37.0-65.0)$ & $58.0(40.0-68.0)$ & 0.19 & $53.5(37.0-65.0)$ & $57.0(41.0-66.0)$ & 0.15 \\
\hline Height (cm) & $163.2(155.0-170.6)$ & $161.0(154.8-171.0)$ & 0.06 & $163.2(155.0-170.6)$ & $162.1(155.5-171.0)$ & 0.02 \\
\hline Weight (kg) & $60.0(53.8-69.0)$ & $64.0(57.3-73.0)$ & 0.41 & $60.0(53.8-69.0)$ & $61.8(55.8-69.2)$ & 0.08 \\
\hline Operation side (Lt/Rt) & $59 / 59$ & 99/98 & 0.01 & $59 / 59$ & $55 / 63$ & 0.07 \\
\hline Local anesthetic $(\mathrm{mL})$ & $25.0(20.0-25.0)$ & $25.0(25.0-25.0)$ & 0.18 & $25.0(20.0-25.0)$ & $25.0(25.0-25.0)$ & 0.01 \\
\hline Pre-operative height of hemidiaphragm (mm) & $5.1(-14.0-14.2)$ & $6.4(-16.1-16.0)$ & 0.02 & $5.1(-14.0-14.2)$ & $7.2(-16.6-16.0)$ & 0.03 \\
\hline
\end{tabular}

Values are presented as number only or median (interquartile range).

CCB: costoclavicular brachial plexus block, SCB: supraclavicular brachial plexus block, ASD: absolute value of standardized mean difference, Lt: left, Rt: right.

Table 2. Outcomes in the CCB and SCB Groups Before and After Propensity Score Matching

\begin{tabular}{|c|c|c|c|c|c|c|}
\hline \multirow[b]{2}{*}{ Characteristic } & \multicolumn{3}{|c|}{ Unmatched data } & \multicolumn{3}{|c|}{ Matched data } \\
\hline & $\begin{array}{l}\text { CCB group } \\
(\mathrm{n}=118)\end{array}$ & $\begin{array}{l}\text { SCB group } \\
(n=197)\end{array}$ & $P$ value & $\begin{array}{l}\text { CCB group } \\
(n=118)\end{array}$ & $\begin{array}{l}\text { SCB group } \\
(n=118)\end{array}$ & $P$ value \\
\hline Postoperative height of hemidiaphragm (mm) & $5.1 \pm 20.1$ & $20.0 \pm 30.4$ & $<0.001$ & $5.1 \pm 20.1$ & $19.1 \pm 28.6$ & $<0.001$ \\
\hline Difference between pre- and post-operative height ( $\mathrm{mm}$ ) & $4.0(-2.0-10.0)$ & $15.0(2.0-38.0)$ & $<0.001$ & $4.0(-2.0-10.0)$ & $13.5(1.0-34.0)$ & $<0.001$ \\
\hline Diagnosis of HDP $(>20 \mathrm{~mm})$ & $3(2.5)$ & $87(44.2)$ & $<0.001$ & $3(2.5)$ & $47(39.8)$ & $<0.001$ \\
\hline Postoperative $\mathrm{SpO}_{2}$ & $98.0(97.0-98.0)$ & $97.0(96.0-98.0)$ & 0.010 & $98.0(97.0-98.0)$ & $97.0(96.0-98.0)$ & 0.035 \\
\hline
\end{tabular}

Values are presented as mean \pm standard deviation, median (interquartile range), or number (\%).

CCB: costoclavicular brachial plexus block, SCB: supraclavicular brachial plexus block, HDP: hemidiaphragmatic paralysis. 
Table 3. Univariate and Multivariate Analyses of Factors Associated with Hemidiaphragmatic Paralysis

\begin{tabular}{|c|c|c|c|c|c|c|}
\hline \multirow{2}{*}{ Characteristic } & \multicolumn{3}{|c|}{ Univariate analysis } & \multicolumn{3}{|c|}{ Multivariate analysis } \\
\hline & OR & $95 \% \mathrm{Cl}$ & $P$ value & OR & $95 \% \mathrm{Cl}$ & $P$ value \\
\hline $\operatorname{Sex}(M)$ & 0.68 & 0.41 to 1.11 & 0.126 & 0.57 & 0.29 to 1.09 & 0.091 \\
\hline Age (yr) & 1.01 & 0.99 to 1.02 & 0.340 & - & - & - \\
\hline Height (cm) & 0.99 & 0.97 to 1.01 & 0.410 & - & - & - \\
\hline Weight (kg) & 1.02 & 1.00 to 1.03 & 0.059 & 1.01 & 0.99 to 1.04 & 0.342 \\
\hline Local anesthetic $(\mathrm{mL})^{\mathrm{a}}$ & 1.12 & 1.04 to 1.21 & 0.004 & 1.11 & 1.02 to 1.22 & 0.014 \\
\hline Block type (CCB) & 0.03 & 0.01 to 0.09 & $<0.001$ & 0.04 & 0.01 to 0.10 & $<0.001$ \\
\hline
\end{tabular}

OR: odds ratio, Cl: confidence interval, CCB: costoclavicular brachial plexus block, -: not available.

${ }^{a}$ Original volume of local anesthetic used minus $15 \mathrm{~mL}$.

$$
\begin{aligned}
\ln \left(\frac{p}{1-p}\right)=-1.12-0.41 \times \text { sex }-3.39 & \times \text { block approach } \\
& +0.11 \times(\text { volume }-15)
\end{aligned}
$$

That is, the exponential of the value calculated on the right-hand side of the equation would be the odds $(p / 1-p)$ of HDP for the given covariates, with a $p>0.5$ predicting HDP. For example, if a CCB using $30 \mathrm{~mL}$ of local anesthetic is performed on a male patient, the calculated $p$ would be 0.037, predicting that HDP will not occur. The HosmerLemeshow goodness-of-fit test yielded a $P$ value of 0.930 , indicating no evidence of poor fit.

\section{DISCUSSION}

This single center retrospective propensity score matched cohort study showed that the incidence of HDP was significantly lower in patients undergoing brachial plexus blocks by the CCB than by the SCB. In addition, the volume of local anesthetic correlated positively with the incidence of HDP.

The brachial plexus block can be an attractive alternative to general anesthesia in patients at high risk of postoperative pulmonary complications due to underlying lung pathology. However, the brachial plexus block, especially the interscalene brachial plexus block, is accompanied by a risk of HDP [3-6], a significant adverse event in these patients [11-13]. In addition, patients may experience respiratory depression and nausea due to perioperative opioid use, although the latter can be reduced by a brachial plexus block. Various strategies have been proposed for diaphragm sparing brachial plexus blocks $[1,8,14,28,29]$. Except for one study, in which $20 \mathrm{~mL}$ of $0.75 \%$ ropivacaine was administered to patients undergoing upper extremity surgery [8], none of the strategies could eliminate the risk completely.

Because the CCB was introduced relatively recently, few studies have evaluated the incidence of HDP associated with it. A randomized control trial using $35 \mathrm{~mL}$ of local anesthetic for the CCB and a paracoracoid infraclavicular approach reported that the rates of HDP were $8.9 \%$ in both groups [30]. Moreover, a recent study using $20 \mathrm{~mL}$ of local anesthetic for the CCB and interscalene brachial plexus block in 44 patients found that the rates of HDP were $0 \%$ and $100 \%$, respectively [22]. The logistic regression model described in this study showed that the likelihood of HDP is 30 -fold lower for the CCB than for the SCB. Although the present study revealed that the incidence of HDP was significantly lower in patients undergoing the CCB than the SCB, three patients who underwent the CCB were diagnosed with HDP.

In theory, use of a higher volume of local anesthetic increases the likelihood of phrenic nerve blockade due to the direct spread of local anesthetic toward the phrenic nerve or rostral spread to the cervical nerve roots [31]. The relationship between local anesthetic volume and HDP has been observed consistently $[3,5,6,8,32]$. For example, randomized controlled trials of patients undergoing the interscalene brachial plexus block $[3,5,6]$ showed that the incidence of HDP in patients who were administered $5 \mathrm{~mL}$ of local anesthetic was $27 \%-45 \%$, about half that of patients who were administered larger volumes of local anesthetic. Studies using a relatively small volume of local anesthetic $(20 \mathrm{~mL})$ reported an incidence of HDP of $0 \%-9 \%$ in patients undergoing SCB $[8,32]$ and a $0 \%$ incidence in patients undergoing CCB [22]. The present study also showed that administration of $<25 \mathrm{~mL}$ of local anesthetic in CCB resulted in a $0 \%$ incidence of HDP. Taken together, these findings indicate that a low local anesthetic volume may prevent HDP in the CCB, a result supported by the multivariate logistic regression analysis performed in this study. According to the model suggested in this study, every $10 \mathrm{~mL}$ of local anesthetic exceeding $15 \mathrm{~mL}$ increases the likelihood of HDP three-fold.

The optimal volume of local anesthetic for the CCB has not yet been determined. Due to the anatomical advantages of the costoclavicular space [21,33], a relatively small 
volume of local anesthetic was administered compared with the conventional infraclavicular brachial plexus block and the results were successful $[19,20,22]$. In contrast, a dose-finding study for ultrasound-guided CСB with $1.5 \%$ lidocaine revealed that the minimum effective volume in $90 \%$ of patients was $34 \mathrm{~mL}$ [10]. The differences among studies may be due to differences in the details of the injection techniques, such as the injection duration and pressure limit, as well as differences in the definition of successful blockade $[10,19,22]$. Several studies have identified the fascial layer within the neurovascular sheath of the brachial plexus $[34,35]$ as a layer that may impede the spread of local anesthetic. In contrast to the single injection technique utilized in the dose-finding study for the CCB [10], the present study used a two-injection technique. This may explain why the relatively low volume of local anesthetic could spread sufficiently to induce successful anesthesia [36]. Further research is required to determine the optimal volume of local anesthetic that can reliably anesthetize the entire upper limb area, including the shoulder joint, while preventing HDP.

The method to detect HDP in this study differed from methods used in previous studies. Most previous studies employed motion mode ultrasonography, which uses the liver and spleen as acoustic windows to monitor the excursions of the diaphragm during the respiratory cycle $[1,8,14,22]$. This method is technically difficult, especially when monitoring the left diaphragm $[37,38]$, as well as being both time consuming and operator dependent [39]. HDP in the present study was determined by the change in the relative position of the hemidiaphragm on chest radiographs. Despite chest radiography having a long clinical history and being a basic diagnostic tool, definitive diagnostic criteria for HDP have not yet been firmly established. The diagnostic cut off value of HDP used in this study was based on previous studies, which showed that the average movement of the diaphragm during tidal breathing was about $1.5-2.0 \mathrm{~cm}[40,41]$. Moreover, the paradoxical upward movement of the hemidiaphragm during sniffing can be up to $2 \mathrm{~cm}$ in some healthy people [42]. We therefore assumed that the difference would be equal or greater when HDP does occur than when it does not, coupled with the detection of the normal paradoxical movement of the hemidiaphragm. We found that a value of $2 \mathrm{~cm}$ corresponds to the 98th and 55th percentiles in the change of height of the hemidiaphragm in the CCB and SCB groups, respectively.

In one study [43], chest radiography showed 0.90 sensitivity and 0.44 specificity in diagnosing HDP, suggesting a low false negative rate and a relatively high false positive rate. Therefore, the diagnostic method described in this study is more likely to overestimate the incidence of HDP, an aspect that can be considered more conservative. Also, HDP in the present study was determined by comparing pre- and postoperative images. We believe that it could reduce the false positive rate due to the inherent differences in height between the two sides and overcome the limitations of a single static imaging modality, at least to some degree.

This study had several limitations, including its retrospective design. We attempted to minimize this limitation by propensity score matching. However, the matching could not sufficiently balance the ages of the two groups. The CCB is apparently preferred for younger patients, and the effect of age on the study results cannot be excluded [44]. In addition, we did not have detailed information regarding block quality or onset. Finally, the diagnostic tool used to detect HDP in the present study differed from that in other studies. Although the technical ease of chest radiography may be a strength of the present study, it limits direct comparison with studies using ultrasonography to detect HDP. Additional studies are needed to determine the correlation between chest radiography and ultrasonography in the diagnosis of HDP.

In conclusion, the results of this study showed that the incidence of HDP was significantly lower in patients undergoing the CCB than the SCB. In addition, the volume of local anesthetic correlated positively with the incidence of HDP.

\section{CONFLICT OF INTEREST}

No potential conflict of interest relevant to this article was reported.

\section{FUNDING}

This work was supported by research fund of Chungnam National University (2019-0529-01) and by the National Research Foundation of Korea (NRF) grant funded by the Korea government (MSIT) (2019R1G1A1099660).

\section{ORCID}

Chahyun Oh, https://orcid.org/0000-0001-8344-4245

Chan Noh, https://orcid.org/0000-0003-4904-148X

Hongsik Eom, https://orcid.org/0000-0001-7386-4430 Sangmin Lee, https://orcid.org/0000-0002-7582-4683 Seyeon Park, https://orcid.org/0000-0002-2471-3174 Sunyeul Lee, https://orcid.org/0000-0002-6124-5138 Yong Sup Shin, https://orcid.org/0000-0001-5071-734X 
Youngkwon Ko, https://orcid.org/0000-0002-0178-6346

Woosuk Chung, https://orcid.org/0000-0002-6409-2325

Boohwi Hong, https://orcid.org/0000-0003-2468-9271

\section{REREFENCES}

1. Kang RA, Chung YH, Ko JS, Yang MK, Choi DH. Reduced hemidiaphragmatic paresis with a "corner pocket" technique for supraclavicular brachial plexus block: singlecenter, observer-blinded, randomized controlled trial. Reg Anesth Pain Med 2018; 43: 720-4.

2. Mak PH, Irwin MG, Ooi CG, Chow BF. Incidence of diaphragmatic paralysis following supraclavicular brachial plexus block and its effect on pulmonary function. Anaesthesia 2001; 56: 352-6.

3. Riazi S, Carmichael N, Awad I, Holtby RM, McCartney CJ. Effect of local anaesthetic volume (20 vs $5 \mathrm{ml}$ ) on the efficacy and respiratory consequences of ultrasound-guided interscalene brachial plexus block. Br J Anaesth 2008; 101: 549-56.

4. Sinha SK, Abrams JH, Barnett JT, Muller JG, Lahiri B, Bernstein BA, et al. Decreasing the local anesthetic volume from 20 to $10 \mathrm{~mL}$ for ultrasound-guided interscalene block at the cricoid level does not reduce the incidence of hemidiaphragmatic paresis. Reg Anesth Pain Med 2011; 36: 17-20.

5. Stundner O, Meissnitzer M, Brummett CM, Moser S, Forstner $\mathrm{R}$, Koköfer A, et al. Comparison of tissue distribution, phrenic nerve involvement, and epidural spread in standard- vs low-volume ultrasound-guided interscalene plexus block using contrast magnetic resonance imaging: a randomized, controlled trial. Br J Anaesth 2016; 116: 405-12.

6. Lee JH, Cho SH, Kim SH, Chae WS, Jin HC, Lee JS, et al. Ropivacaine for ultrasound-guided interscalene block: $5 \mathrm{~mL}$ provides similar analgesia but less phrenic nerve paralysis than 10 mL. Can J Anaesth 2011; 58: 1001-6.

7. Ryu TH, Jeon YH, Lim DG. Postoperative analgesia in dyspneic patient after interscalene brachial plexus block with general anesthesia: a case report. J Korean Pain Soc 2004; 17: 266-70.

8. Renes SH, Spoormans HH, Gielen MJ, Rettig HC, van Geffen GJ. Hemidiaphragmatic paresis can be avoided in ultrasound-guided supraclavicular brachial plexus block. Reg Anesth Pain Med 2009; 34: 595-9.

9. Urmey WF, McDonald M. Hemidiaphragmatic paresis during interscalene brachial plexus block: effects on pulmonary function and chest wall mechanics. Anesth Analg 1992; 74: 352-7.

10. Sotthisopha T, Elgueta MF, Samerchua A, Leurcharusmee P, Tiyaprasertkul W, Gordon A, et al. Minimum effective volume of lidocaine for ultrasound-guided costoclavicular block. Reg Anesth Pain Med 2017; 42: 571-4.

11. Rose M, Ness TJ. Hypoxia following interscalene block. Reg
Anesth Pain Med 2002; 27: 94-6.

12. Erickson JM, Louis DS, Naughton NN. Symptomatic phrenic nerve palsy after supraclavicular block in an obese man. Orthopedics 2009; 32: 368.

13. Gentili ME, Deleuze A, Estèbe JP, Lebourg M, Ecoffey C. Severe respiratory failure after infraclavicular block with $0.75 \%$ ropivacaine: a case report. J Clin Anesth 2002; 14: 459-61.

14. Petrar SD, Seltenrich ME, Head SJ, Schwarz SK. Hemidiaphragmatic paralysis following ultrasound-guided supraclavicular versus infraclavicular brachial plexus blockade: a randomized clinical trial. Reg Anesth Pain Med 2015; 40: 133-8.

15. Dullenkopf A, Blumenthal S, Theodorou P, Roos J, Perschak $\mathrm{H}$, Borgeat A. Diaphragmatic excursion and respiratory function after the modified Raj technique of the infraclavicular plexus block. Reg Anesth Pain Med 2004; 29: 110-4.

16. Rodríguez J, Bárcena M, Alvarez J. Restricted infraclavicular distribution of the local anesthetic solution after infraclavicular brachial plexus block. Reg Anesth Pain Med 2003; 28: 33-6.

17. Kessler J, Schafhalter-Zoppoth I, Gray AT. An ultrasound study of the phrenic nerve in the posterior cervical triangle: implications for the interscalene brachial plexus block. Reg Anesth Pain Med 2008; 33: 545-50.

18. Songthamwat B, Karmakar MK, Li JW, Samy W, Mok LYH. Ultrasound-guided infraclavicular brachial plexus block: prospective randomized comparison of the lateral sagittal and costoclavicular approach. Reg Anesth Pain Med 2018; 43: 825-31.

19. Li JW, Songthamwat B, Samy W, Sala-Blanch X, Karmakar MK. Ultrasound-guided costoclavicular brachial plexus block: sonoanatomy, technique, and block dynamics. Reg Anesth Pain Med 2017; 42: 233-40.

20. Karmakar MK, Sala-Blanch X, Songthamwat B, Tsui BC. Benefits of the costoclavicular space for ultrasound-guided infraclavicular brachial plexus block: description of a costoclavicular approach. Reg Anesth Pain Med 2015; 40: 287-8.

21. Sala-Blanch X, Reina MA, Pangthipampai P, Karmakar MK. Anatomic basis for brachial plexus block at the costoclavicular space: a cadaver anatomic study. Reg Anesth Pain Med 2016; 41: 387-91.

22. Aliste J, Bravo D, Layera S, Fernández D, Jara Á, Maccioni C, et al. Randomized comparison between interscalene and costoclavicular blocks for arthroscopic shoulder surgery. Reg Anesth Pain Med 2019. doi: 10.1136/rapm-2018-100055.

23. García-Vitoria C, Vizuete J, López Navarro AM, Bosch M. Costoclavicular space: a reliable gate for continuous regional anesthesia catheter insertion. Anesthesiology 2017; 127: 712.

24. Nieuwveld D, Mojica V, Herrera AE, Pomés J, Prats A, SalaBlanch X. Medial approach of ultrasound-guided costoclavicular plexus block and its effects on regional perfussion. Rev Esp Anestesiol Reanim 2017; 64: 198-205. 
25. Soares LG, Brull R, Lai J, Chan VW. Eight ball, corner pocket: the optimal needle position for ultrasound-guided supraclavicular block. Reg Anesth Pain Med 2007; 32: 94-5.

26. Lee DK. An introduction to propensity score matching methods. Anesth Pain Med 2016; 11: 130-48.

27. Ho D, Imai K, King G, Stuart EA. MatchIt: nonparametric preprocessing for parametric causal inference. J Stat Softw 2011; 42: 28.

28. Albrecht E, Bathory I, Fournier N, Jacot-Guillarmod A, Farron A, Brull R. Reduced hemidiaphragmatic paresis with extrafascial compared with conventional intrafascial tip placement for continuous interscalene brachial plexus block: a randomized, controlled, double-blind trial. Br J Anaesth 2017; 118: 586-92.

29. Tran DQ, Elgueta MF, Aliste J, Finlayson RJ. Diaphragmsparing nerve blocks for shoulder surgery. Reg Anesth Pain Med 2017; 42: 32-8.

30. Leurcharusmee P, Elgueta MF, Tiyaprasertkul W, Sotthisopha T, Samerchua A, Gordon A, et al. A randomized comparison between costoclavicular and paracoracoid ultrasoundguided infraclavicular block for upper limb surgery. Can J Anaesth 2017; 64: 617-25.

31. El-Boghdadly K, Chin KJ, Chan VWS. Phrenic nerve palsy and regional anesthesia for shoulder surgery: anatomical, physiologic, and clinical considerations. Anesthesiology 2017; 127: 173-91.

32. Aliste J, Bravo D, Fernández D, Layera S, Finlayson RJ, Tran DQ. A randomized comparison between interscalene and small-volume supraclavicular blocks for arthroscopic shoulder surgery. Reg Anesth Pain Med 2018; 43: 590-5.

33. Demondion X, Herbinet P, Boutry N, Fontaine C, Francke JP, Cotten A. Sonographic mapping of the normal brachial plexus. AJNR Am J Neuroradiol 2003; 24: 1303-9.

34. Morimoto M, Popovic J, Kim JT, Kiamzon H, Rosenberg AD.
Case series: septa can influence local anesthetic spread during infraclavicular brachial plexus blocks. Can J Anaesth 2007; 54: 1006-10.

35. Brenner D, Mahon P, Iohom G, Cronin M, O'Flynn C, Shorten G. Fascial layers influence the spread of injectate during ultrasound-guided infraclavicular brachial plexus block: a cadaver study. Br J Anaesth 2018; 121: 876-82.

36. Monzó E, Hadzic A. Costoclavicular approach to the brachial plexus block: simple or double injection? Reg Anesth Pain Med 2019. doi: 10.1136/rapm-2019-100852.

37. Scott S, Fuld JP, Carter R, McEntegart M, MacFarlane NG. Diaphragm ultrasonography as an alternative to whole-body plethysmography in pulmonary function testing. J Ultrasound Med 2006; 25: 225-32.

38. Boussuges A, Gole Y, Blanc P. Diaphragmatic motion studied by m-mode ultrasonography: methods, reproducibility, and normal values. Chest 2009; 135: 391-400.

39. Testa A, Soldati G, Giannuzzi R, Berardi S, Portale G, Gentiloni Silveri N. Ultrasound M-mode assessment of diaphragmatic kinetics by anterior transverse scanning in healthy subjects. Ultrasound Med Biol 2011; 37: 44-52.

40. Wade OL, Gilson JC. The effect of posture on diaphragmatic movement and vital capacity in normal subjects with a note on spirometry as an aid in determining radiological chest volumes. Thorax 1951; 6: 103-26.

41. Wade OL. Movements of the thoracic cage and diaphragm in respiration. J Physiol 1954; 124: 193-212.

42. Alexander C. Diaphragm movements and the diagnosis of diaphragmatic paralysis. Clin Radiol 1966; 17: 79-83.

43. Chetta A, Rehman AK, Moxham J, Carr DH, Polkey MI. Chest radiography cannot predict diaphragm function. Respir Med 2005; 99: 39-44.

44. Lim CY, In J. Randomization in clinical studies. Korean J Anesthesiol 2019; 72: 221-32. 